\title{
O PROCESSO DE CONVERGÊNCIA DO CPC PME/ IFRS SME SOB A ÓTICA \\ DO INTERACIONISMO SIMBÓLICO
}

\section{THE SME IFRS/ PME CPC CONVERGENCE PROCESS UNDER THE OPTICS OF SYMBOLIC INTERACTION}

\author{
Recebido: 25/03/2017 - Aprovado: 16/05/2017-Publicado: 27/06/2017 \\ Processo de Avaliação: Double Blind Review
}

\author{
Tiago de Vasconcelos ${ }^{1}$ \\ Doutorando em Administração \\ Universidade Presbiteriana Mackenzie - UPA \\ Mestrado profissional em Mestrado em Controladoria \\ Universidade Presbiteriana Mackenzie - UPA \\ tiagodevasconcelos@yahoo.com.br
}

\begin{abstract}
RESUMO: O IASB (International Accounting Standards Board), preocupando-se em adequar as Normas Internacionais de Contabilidade para todos os portes de empresas, criou a IFRS (International Financial Reporting Standard) para (PME) Pequenas e Médias Empresas, visando padronizar a contabilidade societária das empresas que não possuem o rigor e a estrutura das empresas de capital aberto. Apesar do Conselho Federal de Contabilidade determinar que as empresas PME se enquadrem ao CPC PME, devido ao pouco nível de estrutura e governança corporativa das empresas, não possuírem a obrigatoriedade de auditoria e a não necessidade de evidenciação dos seus relatórios financeiros ao mercado, muitas empresas não se adaptam ao CPC (Comitê de Pronunciamentos Contábeis) PME. As empresas que convergem ao CPC PME são decorrentes das decisões de seus gestores norteados pelas suas crenças, valores e experiências prévias em empresas que são obrigadas a utilizarem o IFRS para a divulgação dos seus resultados. O objetivo do presente ensaio teórico é refletir sobre o potencial do interacionismo simbólico como abordagem epistemológica para compreender o processo de convergência no Brasil ao CPC PME. Estas crenças, valores e experiências prévias podem ser embasados pelo interacionismo simbólico proporcionando um estilo de gestão que direcione a convergências das empresas PME à adoção das normas internacionais como processo e padrão das regras contábeis na prática.
\end{abstract}

Palavras-chave: IFRS; PME; Convergência; Interacionismo Simbólico.

ABSTRACT: The IASB (International Accounting Standards Board), concerned in adapting the International Accounting Standards for all sizes of companies, created the

\footnotetext{
${ }^{1}$ Autor para correspondência: Universidade Presbiteriana Mackenzie - Rua da Consolação, 930 São Paulo- SP, Brasil - CEP 01302-907.
} 
IFRS (International Financial Reporting Standard) for SME (Small and Medium Enterprises) in order to standardize the corporate accounting to companies that don't have the rigor and structure of public companies. Despite the Certified Public Accounting determine that SMEs companies follow the CPC SMEs rules, due to the low level of structure and corporate governance, don't have audit process and no need for disclosure of their financial reports to the market, many companies do not adapt to the CPC SMEs. Companies that converge to CPC SMEs derive from the decisions of their managers guided by their beliefs, values and previous experiences in companies that are obliged to use IFRS for the dissemination of its results. The objective of this theoretical essay is to reflect about the potential of symbolic interaction as an epistemological approach to understanding the process of convergence of small and medium enterprises in Brazil to CPC SMEs. These beliefs, values and previous experiences can be informed by the Symbolic Interactionism providing a management style that drives the convergence of enterprises SMEs to the adoption of international standards as a process and standard of accounting rules in practice.

Keywords: IFRS. SME; Convergence; Symbolic Interaction.

\section{INTRODUÇÃO}

A promulgação da Lei 11.638/07 trouxe uma série de alterações em relação às práticas contábeis no Brasil, a fim de uniformizar as demonstrações contábeis brasileiras com as normas internacionais de contabilidade, conhecidas como International Financial Reporting Standards (IFRS), amplamente aplicadas em países mais desenvolvidos.

Antunes et al. (2012) afirmam que tais mudanças buscaram melhorar a transparência, a compreensibilidade, a relevância, a uniformidade e a qualidade das informações contábeis para os usuários que utilizam as demonstrações financeiras para análises e tomadas de decisão.

Silva (2013) considera que para perpetrar a convergência entre as normas contábeis brasileiras e as IFRS, o Conselho Federal de Contabilidade (CFC), por meio da Resolução 1.055/05, criou o Comitê de Procedimentos Contábeis, cuja principal função é emitir pronunciamentos técnicos acerca dos procedimentos de contabilidade que devem ser adotados pelas organizações, com base nas normas internacionais que são publicadas e atualizadas pela International Accounting Standard Board (IASB), a entidade internacional responsável pelas IFRS.

O International Accounting Standards Board (IASB), criado em 1973, sendo o organismo internacional que elabora as normas internacionais de contabilidade, as quais atualmente são utilizadas por mais de 120 países do mundo, dentre estes o Brasil. As 
normas internacionais são denominadas: International Financial Reporting Standard IFRS, que precede as International Accounting Standard - IAS.

O IASB foi criado com base em alguns objetivos, os quais atualmente se alicerçam em (IASB, 2010):

a) Desenvolver um conjunto único global com qualidade, exequibilidade e aceite das IFRS e aplicando-as rigorosamente;

b) Considerar as necessidades de informações financeiras pelas economias emergentes e pequenas e médias empresas (PME); e

c) Implementar os processos de convergência das normas contábeis com alta qualidade.

Como pode ser notado nos objetivos apresentados, o IASB não procura atender somente as empresas de capital aberto e entidades de grande porte, mas, também faz parte do seu trabalho observar as especificidades das empresas de pequeno e médio porte.

Sua estrutura conceitual para a preparação e apresentação das demonstrações contábeis internacionais é detalhada pelo Framework for the Preparation and Presentation of Financial Statements.

Neste sentido, diante da exigência regulatória para adoção e convergência aos padrões internacionais de contabilidade, as empresas brasileiras prepararam as suas primeiras demonstrações contábeis consolidadas no padrão IFRS a partir do exercício encerrado em 31 de dezembro de 2010, em comparação com o exercício de 2009. Os requerimentos para a convergência emanam não somente das Leis 11.638/07 e 11.941/09, mas também de outros órgãos reguladores, onde já aprovaram, no todo ou em parte, os atos normativos editados pelo CPC, tais como: a Comissão de Valores Mobiliários (CVM), o Conselho Monetário Nacional (CMN), a Superintendência de Seguros Privados (Susep), a Agência Nacional de Saúde Suplementar (ANS), a Agência Nacional de Transportes Terrestres (ANTT), a Agência Nacional de Energia Elétrica (ANEEL) e o CFC.

As novas regras de Contabilidade aplicáveis às Pequenas e Médias Empresas PME (CPC - PME), em vigor no Brasil desde $1^{\circ}$ de janeiro de 2010, têm aplicação obrigatória no 15 segmento das PME, em decorrência da edição pelo Conselho Federal de Contabilidade - CFC, da NBC T 19.41. A partir da adoção das novas normas de contabilidade no Brasil os contadores devem passar a elaborar demonstrativos alinhados 
a essas normas, e assim, passíveis de usufruir dos benefícios de adoção desse formato de contabilidade que se pretende assumir o status de maior relevância.

De acordo com o CPC PME, são enquadradas como PME as empresas que possuam um faturamento anual de até $\mathrm{R} \$ 300$ milhões ou com ativo total inferior a $\mathrm{R} \$$ 240 milhões, e que não tenham obrigação pública de prestação de contas. Abrange, assim, um contingente expressivo de empresas, já que, segundo dados divulgados pela Organização para Cooperação e Desenvolvimento Econômico (OCDE), essa categoria de empresas representa algo em torno de $95 \%$ das empresas existentes no mundo.

Por meio da Resolução 1.255/09, que aprovou a NBC T 19.41, o CPC PME passou a ser aplicado às PME, cujas normas são consequência direta das "IFRS for SME” (Normas Internacionais de Contabilidade para Pequenas e Médias Empresas), editadas pelo International Accounting Standard Board (IASB), em julho de 2009.

Segundo Santos (2010), a elaboração das IFRS para PME visa nortear as práticas das empresas de capital fechado e, assim, reduzir os problemas relativos ao acesso a financiamento externo, em razão da confiabilidade agregada às suas informações.

Apesar do CFC determinar que as empresas PME se enquadrem ao CPC PME, devido ao pouco nível de estrutura das empresas, não possuírem atividades de auditoria e a não necessidade de evidenciação dos seus relatórios financeiros ao mercado, muitas empresas não tem se adaptado ao CPC PME. O próprio CFC não possui recursos suficientes para a fiscalização de todos os escritórios contábeis e medidas punitivas eficazes.

As empresas que estão seguindo o CPC PME são por decisão de seus gestores ou dos donos do negócio pelas suas crenças, valores ou experiências empresas de porte maiores que possuíam uma cultura de governança corporativa e evidenciação de resultados.

O interacionismo simbólico é uma abordagem importante para o estudo e compreensão da cultura organizacional. Conforme Morgan (1996), falar sobre cultura refere-se ao processo de construção da realidade que permite às pessoas ver e compreender eventos, ações, objetos, expressões e situações particulares de maneiras distintas. Berger e Luckman (1985), a construção e a manutenção da cultura pressupõem que existe um determinado nível de compartilhamento da realidade social edificada pelos membros de um grupo

Numerosas estruturas organizacionais e práticas incorporam padrões de significado subjetivo que são cruciais para o entendimento de como funciona a 
organização no dia a dia. Nesse sentido, Silva e Zanelli (2004) salientam que a perspectiva interacionista simbólica no estudo da cultura organizacional torna-se relevante, uma vez que enfatiza a recuperação do processo de elaboração do universo simbólico ou da construção da realidade de determinada organização social.

Assim, o objetivo do presente ensaio teórico é refletir sobre o potencial do interacionismo simbólico, como abordagem epistemológica, para compreender o processo de convergência das IFRS nas pequenas e médias empresas no Brasil.

Este ensaio teórico é composto por quatro partes, incluindo esta introdução que pretende dar a contextualização do que se pretende refletir; o referencial teórico em que são embasados os principais conceitos discutidos ao longo deste trabalho; a terceira parte em que é evidenciada a relação do interacionismo simbólico e o processo de convergência do CPC PME nas empresas brasileiras e por último; a apresentação das considerações finais. .

\title{
1 - REFERENCIAL TEÓRICO
}

\section{1 - AS PME}

Conforme Deloitte (2010, p. 5), o termo PME - Pequenas e Médias Empresas -, foi definido como:

\begin{abstract}
as sociedades por ações fechadas (sem negociação de suas ações ou outros instrumentos patrimoniais ou de dívida no mercado e que não possuam ativos em condição fiduciária perante um amplo grupo de terceiros), mesmo que obrigadas à publicação de suas demonstrações financeiras, são tidas, para fins deste Pronunciamento, como pequenas e médias empresas, desde que não enquadradas pela Lei $\mathrm{n}^{\circ} 11.638 / 07$ como sociedades de grande porte (sociedades ou conjunto de sociedades sob controle comum que, no exercício social anterior, apresentem ativo total superior a $\mathrm{R} \$ 240$ milhões ou receita bruta anual superior a $\mathrm{R} \$ 300$ milhões).
\end{abstract}

De acordo com o Banco Nacional de Desenvolvimento Econômico e Social (BNDES), a Tabela 1 apresenta a seguinte classificação de empresa por porte: 
Tabela 1 - Classificação de empresa por porte

\begin{tabular}{|c|c|}
\hline Classificação & Receita operacional bruta anual \\
\hline Microempresa & Menor ou igual a $\mathrm{R} \$ 2,4$ milhões \\
\hline Pequena empresa & $\begin{array}{c}\text { Maior que R } \$ 2,4 \text { milhões e menor ou igual a } \mathrm{R} \$ 16 \\
\text { milhões }\end{array}$ \\
\hline Média empresa & $\begin{array}{c}\text { Maior que R\$ } 16 \text { milhões e menor ou igual a } \mathrm{R} \$ 90 \\
\text { milhões }\end{array}$ \\
\hline Média-grande empresa & $\begin{array}{l}\text { Maior que R\$ } 90 \text { milhões e menor ou igual a R\$ } \\
\qquad 300 \text { milhões }\end{array}$ \\
\hline Grande empresa & Maior que $\mathrm{R} \$ 300$ milhões \\
\hline
\end{tabular}

Fonte: BNDES, 2016.

Vale ressaltar que, apesar da classificação formal no ambiente brasileiro, há diversas classificações no mercado, tais como: microempresas, pequenas empresas, empresas de pequeno porte (EPP), médias e grandes empresas.

Em conformidade com o IASB (2010), algumas entidades podem possuir ativos em condições fiduciárias, devido a recursos a elas confiadas por membros não ligados à administração da entidade, mas, se ocorrer por motivos incidentais ao negócio principal, isso não irá obrigá-las a prestar contas publicamente.

Assim, as entidades classificadas como pequenas e médias empresas deverão balizar a elaboração de suas demonstrações financeiras, conforme o IFRS/ CPC para PME, em alguns dos aspectos que serão tratados na quarta seção deste estudo.

Similar às empresas de grande porte, o objetivo das demonstrações financeiras de pequenas e médias empresas é informar os usuários sobre a posição financeira, o desempenho e os fluxos de caixa da entidade, com vistas a fornecer melhores ferramentas para a tomada de decisões.

Segundo Santos (2010), nessas empresas, as demonstrações contábeis têm uso interno (gerencial) e externo (credores, agências de avaliação, sócios que não participam da administração).

De acordo ainda em referência aos aspectos normativos correlatos à atuação das pequenas e médias empresas, a Lei Complementar $n^{\circ} 123$ de 2006, conhecida como "Lei Geral das Pequenas e Médias Empresas" estabelece as normas gerais quanto ao 
tratamento diferenciado e favorecido às microempresas e empresas de pequeno porte no âmbito dos poderes da União, dos Estados, do Distrito Federal e dos Municípios, dispondo sobre a definição e outros aspectos importantes.

Nessa óptica, surge a necessidade de se adaptar as Normas Internacionais de Contabilidade, direcionadas para empresas de grande porte, às empresas de pequeno porte, cumprindo o que é disposto na Constituição Federal, que preza por dar tratamento jurídico diferenciado às entidades classificadas neste grupo, para que, assim, possam ser incentivadas e mais bem assistidas.

\subsection{O COMITÊ DE PRONUNCIAMENTOS CONTÁBEIS - CPC}

O Comitê de Pronunciamentos Contábeis (CPC) foi criado pelo Conselho Federal de Contabilidade (CFC) através da Resolução CFC n ${ }^{\circ}$ 1.055/05 com o objetivo de estudar, preparar e emitir pronunciamentos técnicos, levando sempre em consideração a convergência do padrão contábil brasileiro ao padrão internacional. $\mathrm{O}$ CPC é um comitê autônomo composto por representantes das seguintes instituições: Associação Brasileira das Companhias Abertas (ABRASCA); Associação dos Analistas e Profissionais de Investimento do Mercado de Capitais (APIMEC); Bolsa de Valores, Mercadorias e Futuros (BM\&F BOVESPA); Conselho Federal de Contabilidade (CFC); Fundação Instituto de Pesquisas Contábeis, Atuariais e Financeiras (FIPECAFI) e Instituto dos Auditores Independentes do Brasil (IBRACON).

Além dessas entidades que compõem o CPC, seis representantes, como o CMN, a CVM, a SUSEP, a Secretaria da Receita Federal do Brasil (SRFB), a Confederação Nacional da Indústria (CNI) e a Federação Brasileira dos Bancos (FEBRABAN) foram convidados e participam mensalmente dos trabalhos do CPC.

Em julho de 2009, de acordo com o próprio órgão normativo, o International Accounting Standard Board - IASB emitiu o IFRS para pequenas e médias empresas (SME). Logo depois o Comitê de Pronunciamentos Contábeis - CPC emitiu uma norma equivalente no Brasil o "CPC - PME” em dezembro de 2009.

O CPC PME é um conjunto completo de princípios contábeis, ou seja, não precisa ser lido "em conjunto" com qualquer outra norma, por exemplo, com os demais CPC. A leitura e a aplicação da norma são muito mais simples se comparadas com o 
CPC pleno. Assim como na norma plena, o CPC PME também prevê algumas isenções facultativas quando de sua adoção pela primeira vez, para facilitar o processo.

Em geral o CPC PME pode ser aplicado somente por empresas que não têm obrigação pública de prestação de contas, independentemente de sua forma jurídica.

\subsection{PARADIGMAS DO CPC PME}

O termo PME é empregado, muitas vezes, para designar ou incluir entidades muito pequenas, sem considerar se estas publicam relatórios para usuários externos, partindo do pressuposto de que tais demonstrações são direcionadas somente para atender ao fisco ou apenas como ferramentas gerenciais.

Assim, as autoridades regulatórias de cada jurisdição devem decidir quais empresas devem ou podem recorrer às normas elaboradas pelo IASB. Entretanto esta decisão deve partir da definição descrita pelo IASB (2011), que classifica as PME como entidades que:

(a) não têm obrigação de prestação pública de contas, e;

(b) publicam demonstrações financeiras para fins gerais para usuários externos.

Com exceção das sociedades anônimas e das limitadas de grande porte, os demais tipos de empresa não possuem uma legislação societária específica, sendo, portanto, regidas pelas determinações constantes no Código Civil Brasileiro, Lei 10.406/02, que tratam do Empresário e das Sociedades Empresárias respectivamente. No capítulo IV, a referida legislação discorre sobre a Escrituração do Empresário e da Sociedade Empresária, determinando no art. 1.179:

\footnotetext{
são obrigados a seguir um sistema de contabilidade, mecanizado ou não, com base na escrituração uniforme de seus livros, em correspondência com a documentação respectiva, e a levantar anualmente o balanço patrimonial e o de resultado econômico.
}

O artigo 1.179, em seu segundo parágrafo, a lei dispensa o pequeno empresário de tais exigências, assegurando tratamento diferenciado e simplificado a este e ao empresário rural. No entanto, não há uma definição do que seja o pequeno empresário citado no referido dispositivo legal. O Código Civil determina também a 
obrigatoriedade do Livro Diário, Balancetes Diários e critérios de avaliação de alguns elementos patrimoniais.

As PME carecem de uma legislação societária própria, que as atenda em suas especificidades, pois a Lei 6.404/76, que trouxe determinações às sociedades por ações, é apenas aplicável a estas sociedades. O Regulamento do Imposto de Renda, Decreto $\mathrm{n}^{\circ}$ 3.000/99, dispensa as microempresas e as de pequeno porte da escrituração comercial, exigindo apenas que se sejam mantidos o Livro Caixa, o Livro de Registro de Inventário e a documentação que serviu de base para essa escrituração, enquanto não decorrido o prazo decadencial.

A contabilidade das pequenas e médias empresas está voltada, prioritariamente, para o atendimento tempestivo das exigências fiscais e tributárias, como, por exemplo, compreender a sistemática da Substituição Tributária, o Sistema Público de Escrituração Digital, a Nota Fiscal eletrônica e apuração dos impostos a serem pagos, entre outras.

Para Mandilas, Nikolaidis, Valsamidis e Nikolaidis (2010), o alto custo, a falta de conhecimento, os impactos pelas IFRS para PME e as incertezas gerados, são fatores que as novas normas precisam ponderar. As PME são mais flexíveis, pois as decisões recaem sobre a administração das empresas, sendo estas centradas nos empresários do grupo.

Ainda, segundo Mandilas, Nikolaidis, Valsamidis e Nikolaidis (2010), as IFRS para PME devem ser adaptadas às necessidades de seus usuários, que, neste caso, exigem informações menos justificadas e menos abrangentes.

\subsection{A ORIGEM DO INTERACIONISMO}

De acordo com Blumer (1937), o foco do interacionismo simbólico concentra-se nos processos de interação social, relacionando o comportamento entre indivíduos ou grupos balizados por relações simbólicas.

Blumer (1937), por meio da psicologia social, desenvolveu as primeiras formulações teóricas do interacionismo simbólico e as empregou no estudo do comportamento coletivo e fundamentou o interacionismo simbólico com base em três premissas: 
1) o modo como um indivíduo interpreta os fatos e age perante outros indivíduos ou coisas depende do significado (ou significados) que ele atribui a esses outros indivíduos e coisas;

2) o significado, porém, é resultado dos (ou é construído a partir dos) processos de interação social; e

3) os significados podem sofrer mudanças ao longo do tempo.

As faculdades humanas, tais como o pensamento e a linguagem, interagem reciprocamente com as três premissas mencionadas. O pensamento, ou reflexividade, altera ou modifica as interpretações, enquanto que a linguagem verbal ou a linguagem gestual é um recurso constantemente empregado pelos indivíduos nos processos de interações sociais.

O interacionismo simbólico surgiu em oposição às teorias sociológicas de caráter totalizantes, como o Funcionalismo, que concebe as relações e ações sociais como derivadas das normas e regras sociais pré-estabelecidas.

Além das ações sociais normatizadas pela sociedade, por meio da perspectiva do interacionismo simbólico, há uma enorme variedade de interações sociais que ocorrem de modo a formar coletividades separadas, e que constituem determinados grupos sociais, cada qual com suas regras e normas de conduta, validadas e aceitas pelos indivíduos que os compõem.

Blumer (1937) afirma que as interações sociais são processos dialéticos, pois os indivíduos constroem os grupos e coletividades sociais dos quais fazem parte, e que por sua vez interferem na conduta do indivíduo.

Desta maneira, pode-se colocar em prática as três premissas básicas já citadas: a ação dos atores é derivada da significação; essa significação deriva ou surge das interações sociais; por fim, as significações são empregadas pelos atores sociais nas interações sociais grupais, que, por sua vez, modificam as próprias significações.

\subsection{O INTERACIONISMO SIMBÓLICO}

Blumer (1969) considera que o interacionismo simbólico delineia a vida social por meio de seus símbolos e interações. O símbolo é construído nas interações e dá o sentido da ação individual, assim como coordena as ações interindividuais, sendo 
conduzido pelas dimensões da linguagem-racionalização e a linguagem-expressão, que em suma são formas de representação.

Ainda, de acordo com Blumer (1969), o simbólico é o resultado da interação do sujeito constituído e do sujeito projetado pela linguagem, pela forma de relação que o sujeito está em si e está no outro em interação, construindo a realidade, possibilitando a construção das relações sociais de acordo com o ambiente em que está inserido. $\mathrm{O}$ sentido individual é fundado na construção de um "nós". A linguagem é construção interativo-racional, sua função é estabelecer redes de significação.

Segundo Blumer (1969) o interacionismo simbólico enquanto modelo de pesquisa em ciências sociais, encontra-se inserido no paradigma interpretativista, cujo objetivo é entender o mundo das experiências vividas através do ponto de vista daqueles que nele vivem.

Esta perspectiva simbólico-interpretativa aborda a organização sob uma posição predominantemente subjetivista, procurando entender os significados existentes nas organizações.

Os métodos da pesquisa simbólica-interpretativa, frequentemente, empregam técnicas etnográficas como observação participante e entrevistas etnográficas, que resultam em descrições narrativas e análise de casos. A abordagem subjetivista prevê a filtragem do conhecimento através do pesquisador e, portanto, fortemente impregnado pelas forças cognitivas e culturais.

Os interacionistas simbólicos alocam a pesquisa como uma categoria simbólica baseada na interação, sendo que em seu ponto de vista, a melhor maneira para captar a realidade é aquela em que se possibilita ao pesquisador pôr-se no papel do outro, olhando o mundo pela ótica dos participantes.

A sociologia e a psicologia social são a base da perspectiva interacionista simbólica, possibilita a compreensão do modo como os indivíduos interpretam os objetos e as outras pessoas com as quais interagem e como tal processo de interpretação conduz o comportamento individual em situações específicas.

Autores como Kanter (1972) e Hall (1987) defendem a importância do interacionismo simbólico no estudo da vida social, por apresentar uma percepção dos indivíduos como capazes de utilizar seu raciocínio e poder de simbolização para interpretar e adaptar-se flexivelmente às circunstâncias, dependendo do modo como venham a definir a situação. 
Em contraponto, Mead (1934) concebe a sociedade humana fundamentada na base do consenso, de sentidos compartilhados na forma de compreensões e expectativas comuns. A interação entre os indivíduos perfazem o comportamento, de modo que a as relações dos indivíduos com o mundo externo é realizado por meio de símbolos. O ser humano é sujeito e agente, pois interpreta e simboliza.

Mead (1934) se baseia nas relações de sociedade-individuo-mente como elementos principais do ato social. A mente é a capacidade humana de aprender e usar símbolos que possibilita a comunicação, desta forma para ele, o ato de pensar é uma resposta interior aos símbolos do meio externo.

A natureza da mente é social, uma vez que surge do processo social de comunicação. Blumer (1969), iniciando seus estudos sobre o interacionismo simbólico em 1937, procurou ser fiel ao pensamento de Mead, refletiu sobre a natureza da interação simbólica, a natureza da sociedade e da vida em grupo, a natureza dos objetos, da ação humana e a ação conjunta. Foi estabelecido três premissas básicas do internacionalismo simbólico ou seja: (I) agimos com relação às coisas na base dos sentidos que elas tem para nós; (II) o sentido é derivado da interação social que estabelecemos com os outros; e (III) os sentidos são manipulados e modificados através do processo interpretativo que usamos ao tratar as coisas que encontramos.

O interacionismo simbólico se baseia principalmente no sentido de que as coisas representam para o comportamento humano, no processo de interação dos seus agentes.

Blanco (1988) ao estudar o comportamento humano, considera sua interação mediante comunicações simbólicas, em que os significados das ações podem ser mantidos, modificados ou dados pelos atores, em que o indivíduo atua como mediador entre estes e a organização social, o interacionismo simbólico representa um potencial para compreensão de diferentes aspectos da vida organizacional.

Conforme salienta Coulon (1995), o interacionismo simbólico trouxe às ciências sociais, um lugar teórico para o sujeito social como intérprete do mundo, pondo em prática, com isso, métodos de pesquisa que privilegiam o ponto de vista desses sujeitos.

Benzies e Allen (2001), o objetivo do emprego dessas abordagens é esclarecer e melhor compreender os significados que os próprios sujeitos põem em prática para construir seu mundo social, o que torna o interacionismo simbólico uma perspectiva teórica adequada a pesquisas e investigações qualitativas. Importante realçar que seus pressupostos são também compatíveis com métodos quantitativos, favorecendo os desenhos de pesquisa que se caracterizem pela combinação de múltiplos métodos. 
Reafirma Blumer (1969) que a noção de que o significado é um produto social, uma criação que emana das atividades dos indivíduos, à medida que estes interagem. Conforme esclarece em sua obra, a natureza do interacionismo simbólico tem como base a análise de três premissas: a primeira é que o ser humano orienta seus atos em direção às coisas em função do que estas significam para ele; a segunda é que o significado destas coisas surge como consequência da interação social que cada qual mantém com seu próximo e a terceira é que os significados se manipulam e se modificam mediante um processo interpretativo desenvolvido pela pessoa ao defrontarse com as coisas que vai encontrando em seu caminho.

Blumer (1969) propõe o desenvolvimento de um esquema analítico da sociedade e da conduta humana. O tema central abordado são os processos de interação social; ação social caracterizada por uma orientação imediatamente recíproca, ao passo que o exame desses processos se baseia num conceito específico de interação que privilegia o caráter simbólico da ação social.

Joas (1999) afirma que as relações sociais são vistas como algo aberto e subordinado ao reconhecimento contínuo por parte dos membros da comunidade e não como algo estabelecido de uma vez por todas.

\section{O INTERACIONISMO SIMBÓLICO E A SUA CONTRIBUIÇÃO NA CONVERGÊNCIA DO CPC PME}

Os diversos símbolos em que o indivíduo é exposto, são absorvidos pela mente que por sua vez é uma relação do organismo com a situação, por meio dos gestos, a ideia que há por trás de si e provoca essa ideia no outro indivíduo.

O gesto provoca uma ação, que traz uma reação adequada do outro indivíduo, ocorrendo assim um símbolo que responde a um significado na experiência do primeiro indivíduo e que também evoca esse significado no segundo.

Mead (1934) destaca que o significado é a construção de acordo com a reação regida pelas regras da sociedade, ou conduta social, em que emergem os símbolos significantes. Só quando o indivíduo se identifica com tais símbolos, se torna consciente o significado do indivíduo.

A convergência do CPC PME nas empresas no Brasil, apesar de sua implantação estar vigente e obrigatória, conforme a Resolução CFC 1.255/09 que aprova a NBC T-G 
1000, há um grande número de contadores que ainda não realiza as demonstrações conforme as regras vigentes.

As empresas que convergem ao CPC PME são decorrentes das decisões de seus gestores norteados pelas suas crenças, valores e experiências prévias em empresas que são obrigadas a utilizarem o IFRS para a divulgação dos seus resultados, evidenciando os benefícios da convergência ao IFRS/ CPC por meio de uma maior transparência, controle, facilidade em obtenção de linhas de crédito em instituições financeiras entre outros.

De acordo com Carvalho (2011) o interacionismo simbólico contribui para as associações do indivíduo por meio da sua experiência prévia e símbolos, na construção do seu cenário atual e tomadas de decisão.

\section{CONSIDERAÇÕES FINAIS}

O presente estudo teve como objetivo refletir sobre o potencial do interacionismo simbólico, como abordagem epistemológica, para compreender o processo de convergência das IFRS nas pequenas e médias empresas no Brasil.

Apesar do Conselho Federal de Contabilidade determinar que as empresas PME se enquadrem ao CPC PME a partir de 2010, devido ao pouco nível de estrutura e governança corporativa das empresas, não possuírem a obrigatoriedade de auditoria e a não necessidade de evidenciação dos seus relatórios financeiros ao mercado, muitas empresas não se adaptam ao CPC PME.

Os gestores optam pela convergência ao IFRS SME/ CPC PME por experiências prévias em empresas de porte maiores que possuíam uma cultura de governança corporativa e evidenciação de resultados.

A abordagem interacionista simbólica possibilita uma abordagem alternativa de compreensão da decisão dos gestores e donos das empresas quanto á convergência das empresas de pequeno e médio porte na adoção do IFRS SME/ CPC PME como regras de contabilização da sua contabilidade societária.

Considera-se que é relevante o Conselho Federal de Contabilidade realize uma companha educativa e de conscientização sobre os benefícios gerenciais e 
mercadológicos sobre a padronização contábil para os contadores, controllers, financeiros e gestores das empresas PME.

Como sugestão de novos estudos, pelo fato deste artigo ter apresentado um escopo apenas teórico, recomenda-se a evidenciação empírica com os gestores das empresas PME sob a ótica do interacionismo simbólico.

\section{REFERÊNCIAS}

ANTUNES, Maria Thereza Pompas; GRECCO, Marta Cristina Pelucio; FORMIGONI, Henrique; MENDONÇA NETO, Octávio Ribeiro de. A adoção no Brasil das normas internacionais de contabilidade IFRS: o processo e seus impactos na qualidade da informação contábil. Revista Economia \& Relações Internacionais, São Paulo, v. 10, n. 20, p. 5-19, jan. 2012.

BENZIES, K. M.; ALLEN, M. N. Symbolic interactionism as a theoretical perspective for multiple method research. Journal of Advanced Nursing, v. 33, n. 4, p. 541- 547, 2001.

BERGER, P. L.; LUCKMANN, T. (1976). A construção social da realidade. Petrópolis: Vozes, 1985.

BLANCO, A. Cinco tradiciones en la psicología social. Madrid: Ediciones Morata, 1988.

BLUMER, H. Man and society. New York: Prentice-Hall, 1937.

BLUMER, H. El interaccionismo simbolico: perspectiva y metodo. Barcelona: Hora, 1969.

BNDES. Banco Nacional de Desenvolvimento Econômico e Social. Disponível em: $<$ http://www.bndes.gov.br/SiteBNDES/bndes/bndes_pt/Institucional/Apoio_Financeiro/ porte.html> Acesso em: 31 mar. 2016.

BRASIL. Lei $\mathbf{n}^{\mathbf{0}}$ 6.404/76, de 15 de Dezembro de 1976. Dispõe sobre sociedade por ações. Disponível em: <http://www.planalto.gov.br/cciviL_03/leis/L6404compilada.htm>. Acesso em: 31 mar. 2016

BRASIL. Lei $\mathbf{n}^{\mathbf{0}} \mathbf{1 0 . 4 0 6 / 0 2}$, de 10 de Janeiro de 2002. Introdução ao direito brasileiro. Disponível em: <http://www.planalto.gov.br/ccivil_03/leis/2002/110406.htm>. Acesso em: 31 mar. 2016.

BRASIL. Lei complementar $n^{0}$ 123/06, de 14 de Dezembro de 2006. Disponível em: <http:// http://www.planalto.gov.br/ccivil_03/leis/LCP/Lcp123.htm>. Acesso em: 31 mar. 2016. 
BRASIL. Lei $\mathbf{n}^{\circ}$ 11.638/07, de 28 de Dezembro de 2007. Dispõe sobre a elaboração e divulgação de demonstrações financeiras. Disponível em: <http:// http://www.planalto.gov.br/ccivil_03/_ato2007-2010/2007/lei/111638.htm>. Acesso em: 31 mar. 2016.

BRASIL. Lei $\mathbf{n}^{0}$ 11.941/09, de 27 de Maio de 2009. Disponível em: <http://www.planalto.gov.br/ccivil_03/_ato2007-2010/2009/lei/111941.htm >. Acesso em: 31 mar. 2016.

BRASIL. Decreto $n^{0}$ 3.000/99, de 26 de Março de 1999. Regulamenta a tributação, fiscalização, arrecadação e administração do Imposto sobre a Renda e Proventos de Qualquer Natureza. Disponível em: <http://www.planalto.gov.br/ccivil_03/decreto/d3000.htm>. Acesso em: 31 mar. 2016

CARVALHO, V. D. Interacionismo Simbólico: origens, pressupostos e contribuições aos estudos organizacionais. Administração: Ensino e Pesquisa, v. 12, n. 4, p. 583607, 2011.

CFC - CONSELHO FEDERAL DE CONTABILIDADE. Resolução CFC 1.055/05, de 07 de Outubro de 2005. Cria o Comitê de Pronunciamento Contábeis. Disponível em: <http:// http://www.cfc.org.br>. Acesso em: 23 mar. 2016.

CFC - CONSELHO FEDERAL DE CONTABILIDADE Resolução CFC 1.255/09, de 07 de Outubro de 2005. Aprova a NBC TG 1000 - Contabilidade para Pequenas e Médias Empresas. Disponível em: <http:// http://www.cfc.org.br>. Acesso em: 23 mar. 2016.

COULON, A. A Escola de Chicago. Campinas: Papirus, 1995.

CPC - COMITÊ DE PRONUNCIAMENTO CONTÁBEIS. CPC PME (R1). Pronunciamento Técnico PME Contabilidade para Pequenas e Médias Empresas. Disponível em: <http://www.cpc.org.br/CPC/Documentos emitidos/Pronunciamentos/Pronunciamento?Id=79>. Acesso em: 31 mar. 2016.

DELOITTE. IFRS para PME ao seu alcance - 2010. Disponível em: <http://www.deloitte.com.br/publicacoes/2007/Pocket_PME.pdf.> Acesso em: 31 mar. 2016.

IASB. About the IASC Foundation and the IASB. 2010. Disponível em: <http://www.iasb.org/The+organisation/IASCF+and+IASB.htm> Acesso em31 mar. 2016.

IASB. A guide to the IFRS for SMEs 2010. Disponível em: <www.ifrs.org/NR/rdonlyres/...FAC8.../GuideToIFRSforSMEs2010Oct.pdf>. Acesso em: 28 jul. 2010 b.

JOAS, H. Interacionismo simbólico. In: GUIDDENS, A.; TURNER, J. Teoria social hoje. São Paulo: Unesp, 1999. 
MANDILAS, A., NIKOLAIDIS, M., VALSAMIDIS, S., NIKOLAIDIS, A. An Empirical Study on the Adoption of IFRS for SMEs: the Case of Kavala, Greece. Management of International Business and Economic Systems (MIBES). International Conference. Kavala-Grécia. 4-6 de Junho 2010.

MEAD, G. H. Espiritu, persona y sociedad: desde el punto de vista del condutismo social. Barcelona: Paidos, 1934.

MORGAN, G. Imagens da Organização. São Paulo: Atlas, 1996.

SANTOS, A. IFRS para pequenas e médias empresas. 2010. Disponível em: <www.anefac.com.br/artigos/ibef30-06.pdf>. Acesso em: 31 mar. 2016.

SILVA, N.; ZANELLI, J. C. Cultura organizacional. In: ZANELLI, J. C.; BORGESANDRADE, J. E.; BASTOS, A. V. B. (Orgs.). Psicologia, organizações e trabalho no Brasil. Porto Alegre: Artmed, 2004.

SILVA, Ricardo Luis Menezes da. Adoção completa das IFRS no Brasil: qualidade das demonstrações contábeis e o custo de capital próprio. 2013. 219 f. Tese (Doutorado em Ciências) - Curso de Pós-Graduação em Controladoria e Contabilidade, Universidade de São Paulo, São Paulo, 2013. 